\section{Category}

Organo- and

Biocatalysis

\section{Key words}

\section{umpolung}

conjugate addition

thiazolium salts

aldehydes

alkenones

alkenoates

\section{Syníact}

H. STETTER* (RWTH AACHEN, GERMANY)

Catalyzed Addition of Aldehydes to Activated Double Bonds - A New Synthetic Approach

Angew. Chem. Int. Ed. 1976, 15, 639-647.

\title{
The Stetter Reaction
}

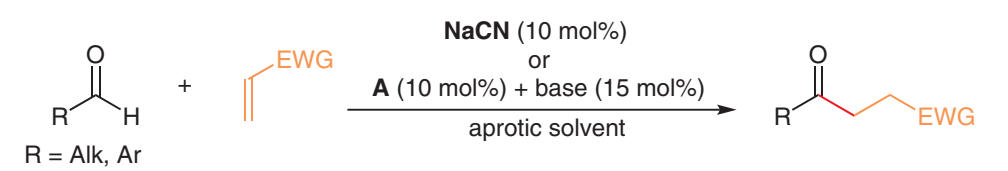

$\mathrm{EWG}=\mathrm{C}(\mathrm{O}) \mathrm{R}, \mathrm{CO}_{2} \mathrm{R}, \mathrm{CN}$

Selected examples:<smiles>CC(=O)CCC(=O)[Ga][Mg]</smiles>

$78 \%$ yield $(71.8 \mathrm{~g})$<smiles>N#CCCC(=O)c1ccccc1</smiles>

$80 \%$ yield $(9.5 \mathrm{~g})$

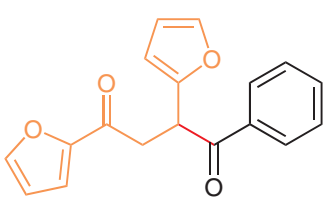

$82 \%$ yield $(12.0 \mathrm{~g})$<smiles>CCCC(=O)CC1CCc2ccccc2C1=O</smiles>

$72 \%$ yield $(32.8 \mathrm{~g})$

First report of an asymmetric Stetter reaction (D. Enders):

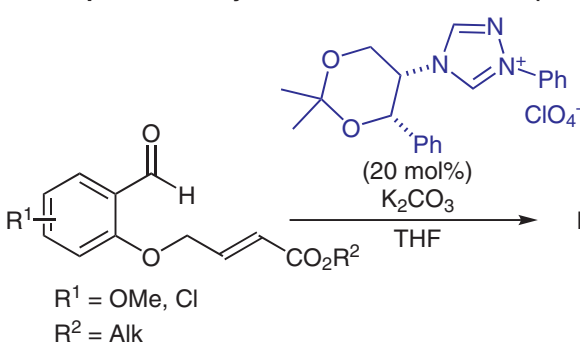

Catalytic cycle:
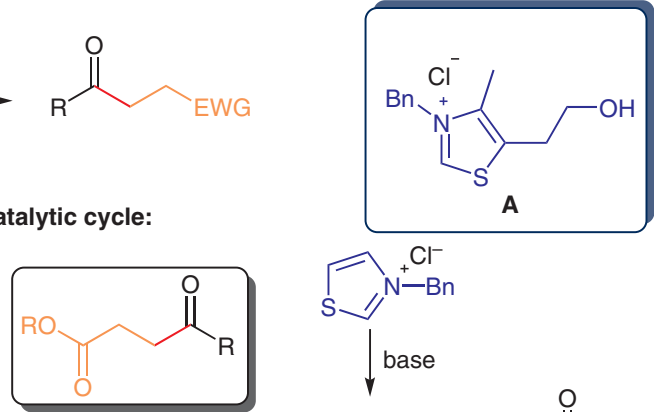

$\overbrace{\mathrm{N}-\mathrm{Bn}}^{\mathrm{Cl}^{-}}$ tion to form C-C-bonds, furnishing a broad range of important products, such as 1,4-diketones, 4keto carboxylic acids, or 4-keto nitriles.
Comment: The utility and applicability of this methodology was rapidly recognized by the scientific community. For example, Trost and co-workers applied the Stetter reaction in the total synthesis of rac-hirsutic acid C (J. Am. Chem. Soc. 1979, 101, 1284) shortly after the initial report. Enders and coworkers utilized a chiral triazolium salt (Helv. Chim. Acta 1996, 79, 1899) for the first asymmetric intramolecular Stetter reaction, providing enantioenriched chromanones. To the present day, 1,4-dicarbonyl compounds and their analogues are frequently synthesized in both academia and industry by employing the Stetter reaction. 